\title{
Discrimination in Healthcare, Experiences of Nurses, Physicians and Patients: A Qualitative Content Analysis
}

\section{Mohammad javad Hosseinabadi-farahani}

University of Social Welfare and Rehabilitation Science https://orcid.org/0000-0002-1132-5914

Masoud Fallahi-khoshknab ( $\square$ msflir@yahoo.com )

Professor in Nursing, Department of Nursing, University of social Welfare and Rehabilitation Sciences,

Tehran, Iran. https://orcid.org/0000-0003-0507-0107

\section{Narges Arsalani}

University of Social Welfare and Rehabilitation Science

\section{Mohammadali Hosseini}

University of Social Welfare and Rehabilitation Science

\section{Eesa Mohammadi}

Tarbiat Modares University Faculty of Medical Sciences

\section{Research article}

Keywords: Justice, Discrimination, Healthcare, Qualitative Study, Content Analysis

Posted Date: February 17th, 2021

DOl: https://doi.org/10.21203/rs.3.rs-229654/v1

License: (c) (i) This work is licensed under a Creative Commons Attribution 4.0 International License. Read Full License 


\section{Abstract}

Background: Justice in health is one of the main concerns of health organizations, and discrimination in health care is one of the negative outcomes to achieving this goal. Hence, a full understanding of the phenomenon of discrimination in health care and adopting strategies to eliminate it is necessary. The present study was conducted to determine the experiences of nurses, physicians, and patients of discrimination in health care.

Methods: The present qualitative content analysis study was conducted between 2019 and 2020. Data were collected through semi-structured interviews with 18 participants (2 physicians, 3 nursing supervisors, 2 head nurses, 4 clinical nurses, 2 nursing assistants, and 3 hospitalized patients) in one public and one private hospital in the city of Tehran. The participants were selected by purposive sampling, which continued until saturation of data. Data obtained were analyzed using Graneheim and Lundman method.

Results: Four main categories and 14 subcategories were extracted from data analysis: 1) Habitual discrimination (everyday discrimination in health centers, ignoring patient rights, low levels of trust in medical staff); 2) interpersonal relationships (expectations of associates, respect for colleagues and friends, the possibility of the occurrence of similar situations, reciprocating people's favors); 3 ) shortage of health care resources (shortage of medical equipment, heavy workload, infrastructures of medical centers, lack of access to physicians); and 4) Favoritism (ethnicity, favoritism as a common method, and as the ultimate solution to problems).

Conclusion: The present study revealed certain dimensions of discrimination in health care that remain hidden in many quantitative studies. Thus, it appears that health system managers will be able to move towards eliminating discrimination in health care and providing ethical care by considering these issues and adopting appropriate strategies.

\section{Background}

Justice in health is recognized as one of the principles of medical ethics and a primary patient right (1). The International Society for Justice in Health defines this concept as follows: Justice in health means the absence of systematic and potentially resolvable disparities in one or more aspects of health in a population and economic, social, demographic, and geographical subgroups (2). Accordingly, the opposite of justice in health care is discrimination, which has been recognized as one of the negative outcomes (3). Discrimination in health care means non-provision, incomplete provision, or variable provision of health care to individuals, or groups of individuals, because of their personal and social attributes (4). Discrimination in health care is a matter that is experienced by many people but reported only by some (5), who often belong to minority groups in terms of race, ethnicity, or having certain diseases or particular conditions such as physical and mental disabilities (6). Many studies have reported various forms of discrimination in health care such as discrimination based on sex (7), race/ethnicity (8), 
age (9), disease type and nature, religion (10), language (11), and economic level and social status (12). In all these cases, patients and visitors to medical centers have received partial, poor quality, or different health care services compared to other patients.

In explaining the current situation, Javier \& Luis (2013) reported three common forms of discrimination in health care in the EU member states, namely, age, sex, and disability discriminations. Among European countries, Britain and Cyprus had the highest and lowest reports of discrimination in health care, respectively. Low income and high-school education were among the factors blamed for discrimination in health care (13).

In the United States of America, John D. Piette states that almost one-third of patients visiting health centers had experienced discrimination in receiving health care during their lifetime (14). In Heuvel's study (2011) investigating the experience of discrimination among older European citizens, 26\% of 62-year-old citizens had experienced age discrimination occasionally and $11 \%$ constantly (15). In his study, Rodriguez (2017) reported that at least one in ten Hispanic immigrants' experiences discrimination in receiving health care (16).

Discrimination in health care has significant consequences, and one of the most important of these consequences is visitor's and patients' loss of confidence in medical staff. Other important consequences include exposure to stress and experience of further tensions- with their specific complications, anxiety, depression, rising blood pressure, and even risk factors for developing certain health problems such as obesity, breast cancer, and drug abuse (17-21).

To accomplish justice and fight discrimination in health care provision, various organizations, WHO in particular, have designed and implemented varied strategies. These strategies include continuous education of health care providers on ethical principles, the constant review of health care policies, and providing support to the public and stressing the need for people to report discrimination encountered in clinical settings $(11,22)$. However, discrimination in providing health care remains a major challenge and barrier (23-26). The inadequacy of these policies and strategies suggests that strategies implemented have not been based on a comprehensive knowledge of the dimensions of discrimination in health care, and insufficient knowledge of the phenomenon of discrimination and its dimensions is probably one of the reasons for the inadequacy of such programs. Furthermore, most studies conducted on discrimination in health care have been quantitative and reported its frequency and adverse consequences and causes and subjective aspects of discriminatory behaviors of health care providers have been less studied. Moreover, the phenomenon of discrimination in health care is influenced by various sociocultural factors and experienced differently by people in different societies (27-30), and therefore, a full understanding of this phenomenon is necessary for adopting effective discrimination control and elimination strategies. Hence, the present study was conducted to determine the experiences of nurses, physicians, and patients of discrimination in health care.

\section{Methods}


The present qualitative study was conducted between June 2019 and July 2020 and used the content analysis approach to explain the phenomenon of discrimination in health care using the experiences of patients and medical staff and explain the process of unintentional discrimination among health service providers and their experiences. The conventional content analysis approach was used to achieve the study objectives as it is a suitable approach for explaining people's experiences (31). The study setting comprised two hospitals in Tehran, the capital of Iran, one of which was a public teaching hospital, and the other was private and not a teaching hospital. Both hospitals provided specialized and subspecialty medical services.

\section{Participants}

The participants included 18 people, of whom, 15 were health service providers (physicians and nurses), and three were patients, who had been purposively selected with maximum diversity in demographic characteristics (age, gender, work history, etc.). The participants' demographic details and diversity are presented in Tables 1 and 2, respectively. 
Table 1

Demographic Characteristics of the Participants.

\begin{tabular}{|c|c|c|c|c|c|c|c|}
\hline Number & $\begin{array}{l}\text { Age } \\
\text { (Years) }\end{array}$ & Gender & $\begin{array}{l}\text { Marital } \\
\text { status }\end{array}$ & Education & Position & $\begin{array}{l}\text { Work } \\
\text { experience } \\
\text { (Years) }\end{array}$ & $\begin{array}{l}\text { Duration } \\
\text { of } \\
\text { interview } \\
\text { (Minutes) }\end{array}$ \\
\hline P1 & 38 & Male & Married & $\begin{array}{l}\text { Master in } \\
\text { nursing }\end{array}$ & $\begin{array}{l}\text { Clinical } \\
\text { Supervisor }\end{array}$ & 16 & 35 \\
\hline P2 & 32 & Female & Single & $\begin{array}{l}\text { Bachelor } \\
\text { in nursing }\end{array}$ & $\begin{array}{l}\text { Nurse of } \\
\text { gynecology } \\
\text { ward }\end{array}$ & 8 & 20 \\
\hline P3 & 40 & Male & Single & M.D & $\begin{array}{l}\text { Emergency } \\
\text { Physician }\end{array}$ & 16 & 24 \\
\hline P4 & 53 & Female & Married & $\begin{array}{l}\text { Bachelor } \\
\text { in nursing }\end{array}$ & $\begin{array}{l}\text { Clinical } \\
\text { Supervisor }\end{array}$ & 28 & 27 \\
\hline P5 & 52 & Female & Married & $\begin{array}{l}\text { Bachelor } \\
\text { in nursing }\end{array}$ & $\begin{array}{l}\text { Clinical } \\
\text { Supervisor }\end{array}$ & 25 & 30 \\
\hline P6 & 33 & Male & Married & $\begin{array}{l}\text { Bachelor } \\
\text { in nursing }\end{array}$ & ICU Nurse & 8 & 33 \\
\hline P7 & 32 & Male & Single & $\begin{array}{l}\text { Bachelor } \\
\text { in nursing }\end{array}$ & ICU Nurse & 10 & 28 \\
\hline P8 & 35 & Female & Married & Diploma & $\begin{array}{l}\text { Nursing } \\
\text { Assistant }\end{array}$ & 12 & 25 \\
\hline P9 & 38 & Female & Married & $\begin{array}{l}\text { Bachelor } \\
\text { in nursing }\end{array}$ & $\begin{array}{l}\text { Head nurse of } \\
\text { surgical ward }\end{array}$ & 15 & 23 \\
\hline P10 & 48 & Male & Married & M.D & Anesthesiologist & 22 & 28 \\
\hline P11 & 36 & Male & Married & Diploma & $\begin{array}{l}\text { Nursing } \\
\text { Assistant }\end{array}$ & 10 & 35 \\
\hline P12 & 48 & Female & Married & $\begin{array}{l}\text { Masters in } \\
\text { nursing }\end{array}$ & $\begin{array}{l}\text { Head nurse of } \\
\text { medical ward }\end{array}$ & 25 & 41 \\
\hline P13 & 42 & Female & Single & $\begin{array}{l}\text { Bachelor } \\
\text { in nursing }\end{array}$ & $\begin{array}{l}\text { Nurse of clinic } \\
\text { ward }\end{array}$ & 16 & 30 \\
\hline P14 & 39 & Female & Married & $\begin{array}{l}\text { Bachelor } \\
\text { in nursing }\end{array}$ & Head Nurse & 15 & 24 \\
\hline P15 & 54 & Female & Married & Bachelor & Patient & 25 & 36 \\
\hline P16 & 41 & Female & Single & Masters & Patient & 16 & 33 \\
\hline P17 & 38 & Female & Married & Masters & Patient & 10 & 24 \\
\hline
\end{tabular}




\begin{tabular}{|llllllll|}
\hline Number & $\begin{array}{l}\text { Age } \\
\text { (Years) }\end{array}$ & Gender & $\begin{array}{l}\text { Marital } \\
\text { status }\end{array}$ & Education & Position & $\begin{array}{l}\text { Work } \\
\text { experience } \\
\text { (Years) }\end{array}$ & $\begin{array}{l}\text { Duration } \\
\text { of } \\
\text { interview } \\
\text { (Minutes) }\end{array}$ \\
\hline P18 & 40 & Female & Married & Bachelor & $\begin{array}{l}\text { Emergency } \\
\text { Nurse }\end{array}$ & 16 & 23 \\
\hline
\end{tabular}

Table 2

Diversity of demographic characteristics of the participants.

Number of
participants

\begin{tabular}{|ll|}
\hline Age (Years) & Mean:41 years, Minimum:32 years, Maximum: 54 years \\
\hline $\begin{array}{l}\text { Gender } \\
\text { Education }\end{array}$ & $\begin{array}{l}\text { Medical doctor: } 2 \text { people, Masters: } 4 \text { people, Bachelor:10 people, Diploma: } 2 \\
\text { people }\end{array}$ \\
$\begin{array}{l}\text { Work experience } \\
\text { (Years) }\end{array}$ & Mean: 16.3 years, Minimum:8 years, Maximum: 28 years \\
\hline Marital status & Married: 13 people, Single: 5 people \\
\hline
\end{tabular}

\section{Data collection}

Data were collected through semi-structured interviews, which started with general questions such as: "Have you ever acted unevenly toward patients? Please describe your experience", and "Have you ever experienced discrimination in receiving medical services?", and then, the next questions were designed based on the interviewee's responses. Prior arrangements were made with the participant regarding the time and place of the interview. Interviews lasted between 20 minutes and 41 minutes each, depending on the participants' conditions and willingness.

\section{Data analysis}

Data were analyzed by the conventional content analysis approach using Graneheim and Lundman method (32). All interviews were conducted, recorded, transcribed, reviewed, and coded, and immediately analyzed by the researcher. Following the content analysis process, each interview was carefully studied several times to obtain an initial and comprehensive understanding of it, and then, important statements in it were highlighted. Next, to clarify the meaning, similar semantic units were extracted and assigned to categories and subcategories. In fact, data were analyzed continuously as they were being collected. To add further data, the process of data collection continued until saturation.

\section{Rigor of data}

For data validation, Strauss, and Corbin method (2015) was used, which combines the criteria proposed by various researchers (33). Accordingly, long-term engagement and contact with the participants helped 
the researcher gain their trust and understand their experiences. Moreover, data credibility methods were used, through the review of the transcripts by participants (member check), to resolve any coding ambiguities. To this end, the researcher made parts of the interviews and codes available to the participants to reach identical concepts on their statements. Confirmability of the data was achieved through systematic data collection, researchers' impartiality, and members' agreement on interviews, codes, and grouping of similar codes and categories and comparison of the researcher's impression with what participants had meant. Dependability of data was achieved by taking notes at the earliest, using peer check, and reviewing the whole data again.

\section{Results}

The participants included 15 health service providers ( 2 physicians, 3 nursing supervisors, 2 head nurses, 4 clinical nurses, and 2 nursing assistants), and 3 hospitalized patients. The participants were aged between 32 years and 53 years. Table 1 presents the demographic details of the participants. The results showed four main categories: 1) habitual discrimination, 2) interpersonal relationships, 3) shortage of health care resources, and 4) favoritism (Table 3).

Table 3. "Discrimination in healthcare" with categories, subcategories, and open codes. 


\begin{tabular}{|c|c|c|}
\hline Category & Subcategory & Open code \\
\hline \multirow{14}{*}{$\begin{array}{l}\text { Involvement with } \\
\text { discrimination }\end{array}$} & \multirow[t]{3}{*}{ Habitual discrimination } & $\begin{array}{l}\text { Discrimination being routine in medical } \\
\text { centers }\end{array}$ \\
\hline & & Ignoring patient rights \\
\hline & & Lack of trust in medical personnel \\
\hline & \multirow[t]{4}{*}{ Interpersonal relationships } & Expectations of acquaintances \\
\hline & & Respect for colleagues and friends \\
\hline & & Likelihood of similar situations \\
\hline & & Reciprocating people's favors \\
\hline & \multirow[t]{4}{*}{$\begin{array}{l}\text { Shortage of health care } \\
\text { resources }\end{array}$} & $\begin{array}{l}\text { Shortage of medical equipment and } \\
\text { facilities }\end{array}$ \\
\hline & & Heavy workload \\
\hline & & Infrastructures of medical centers \\
\hline & & Lack of access to physician \\
\hline & \multirow[t]{3}{*}{ Favoritism } & Discrimination in care due to ethnicity \\
\hline & & Favoritism as a common method \\
\hline & & Ultimate solution to treatment problems \\
\hline
\end{tabular}

Category one: Habitual discrimination

This category means that the phenomenon of discrimination in medical settings like hospitals is constantly experienced as a common and routine phenomenon, and health service providers and recipients consider it to be normal. This category consists of the following subcategories: 1) everyday discrimination in medical centers, 2) ignoring patient rights, and 3) low level of trust in medical staff.

\subsection{Everyday discrimination in medical centers}

This subcategory includes the discriminatory provision of medical services by physicians, nurses, and other health care providers to patients with different conditions. In fact, health service providers declared this as a normal, and even inseparable, part of providing health care in medical centers. For example, participant 3 described: "Discrimination happens in hospitals one hundred percent, and as a doctor, I differentiate between patients. My job is partly based on discrimination, and I consider various issues in my work". (P3) 
Moreover, participant 4 said: "Is no discrimination possible at all? People and the structure of medical centers are such that discrimination is observed in many areas, and its absence is almost abnormal". (P4)

\subsection{Ignoring patient rights}

This subcategory is concerned with patients experiencing a lack of attention from medical staff during doctor's visits and in matters such as patient's condition and appointment time when patients attend medical centers and clinics to receive outpatient medical services. After such an experience, patients attempt to establish contact by searching for an acquaintance in these medical settings. One patient explained: "Given my condition, I consider it right to resort to favoritism. Perhaps, if the clinic's appointment system worked properly, I wouldn't be so inclined to do that. I made an appointment at a clinic and was told to come at a certain time, but, after arriving there, I had to wait for two hours and 45 minutes; why? Why shouldn't they value my time? If that is the case, then I am forced to use favoritism, so that I can be seen quicker". (P17)

\subsection{Lack of trust in medical staff}

In this subcategory, the participants stated that until there is total trust between medical staff (including physicians and nurses) and patients, discrimination between patients will persist in medical settings. In fact, patients not trusting physicians' and nurses' performance look for a mediator to be assured of the performance of health care providers. Participant 10 stated:

"For example, they tell us to be more alert; and not to leave the operating room for one moment, or keep checking the patient's condition in ICU afterward; more accurate treatment and more checking; at the time of anesthesia, make sure that anesthetics are administered at the right dose, and the like". (P10)

A patient in the cardiac critical care unit (CCU) stated:

"I can say that the only reason I come to this hospital is that my good friend, who is a nurse, works here, and I know that she knows her job at the CCU well. My mind is at rest because my friend is here, and I am sure that the things she does are definitely right. She will tell me if something is wrong, and somehow, I am fully informed about the treatment process". (P15)

Category two: Interpersonal relationships

This category refers to instances where medical personnel favor their colleagues or family members of their colleagues and associates in providing health care because of their working relationships. This category consists of the following subcategories: 1) expectations of associates, 2) respect for colleagues and friends, 3 ) the possibility of the occurrence of similar situations, and 4) reciprocating people's favors.

\subsection{Expectations of associates}


In this subcategory, medical staff described their discriminating conduct toward patients because of previous acquaintances with some of them, as well as the expectations of these acquaintances to receive exclusive and more health services. Participant 12 explained:

"Right now, I have a patient who is a young doctor from a province; she had gastrectomy, was taken to the operating room twice. She expects more as she knows more. She is a colleague after all. For instance, she asks for opioids, and at first, I tell her that she cannot have more, but she insists and I give her an injection in the end, but I worry about the risk of apnea. Or, colleagues come here and say that since they have been working in this hospital for so many years, they have certain expectations, and want them to be fulfilled". (P12)

\subsection{Respect for colleagues and friends}

In this subcategory, medical staff (physicians and nurses) cited their friendly relationships with colleagues and their desire to maintain mutual respect and relationship with colleagues as the grounds for discriminating between patients in particular situations. When colleagues or their family members were hospitalized, the staff treated them differently compared to other patients and argued that the reason for providing different health care to this group was that they wanted to show respect toward colleagues. Participant 3 stated:

"For me, there is no difference between patients, whether I know them or not. But, when a colleague's father is admitted, I may check over him more frequently, since it is a friend's father after all, and we are in constant contact, and I am expected to attend to this patient more". (P3)

\subsection{Possibility of the occurrence of similar situations}

This subcategory concerns the possibility that medical staff or their family members may find themselves in a situation where their colleagues in other medical centers could provide them with preferential and different care compared to other patients. Bearing this possibility in mind, medical staff provide their colleagues with preferential care. In fact, based on the idea that the same could happen to them, physicians, nurses. and other medical personnel provide different and fuller medical and nursing care compared to what they do for ordinary patients. Participant 4 stated:

"I attend more to a patient that is a relative of a colleague or a friend and attend to them with greater care and sensitivity. I do this because she is a nurse too, and one day one of my relatives can be hospitalized". (P4)

\subsection{Reciprocating people's favors}

According to this subcategory, the medical staff show discriminatory behaviors in providing preferential care and services to reciprocate for favors they have received from their colleagues in the past.

Participant 9 said: 
"I do this for my colleagues and friends, because of the friendship I have with them. I jump the queue to make an appointment for my friend's mother because she has done the same for me in the past or will do so in the future. It is like give and take. I make up for her trouble". (P9)

Category three: Shortage of health care resources

This category deals with essential items needed for providing health care to patients and visitors, but the shortage of resources, which is seen and experienced by both recipients and providers of medical services, leads to discrimination between patients. This category includes the following subcategories: 1) Shortage of medications and medical facilities and equipment, 2) heavy workload, and 3) lack of access to physicians; and 4) medical centers' infrastructures.

\subsection{Shortage of medications and medical facilities and equipment}

In this subcategory, shortage of medical equipment such as ventilators and ICU beds and also vital medications, on which patients' health depends, creates a situation in which these services are provided preferentially to people who are in a particular condition or are associated with or recommended by a particular person or organization. The shortage of medical equipment also causes physicians and nurses to unintentionally differentiate between patients. For example, participant 6 explained:

"Better care is provided in intensive care units than in regular wards because in the wards, I, as a nurse, have eight to ten patients to care for; one of them is intubated, and I don't have the time or even a monitor to constantly check the patient. There, I am forced to differentiate between patients, and can only attend for two hours of the entire 12-hour shift to this patient because I don't have the time or the necessary equipment". (P6)

\subsection{Heavy workload}

The shortage of physicians, nurses, and other health service providers leads to non-provision of the necessary care and even reduced quality of services and subjects the medical staff to heavy workloads. This forces them to discriminate in providing health care. Participant 9 stated:

"As a head nurse, human resources are especially important to me. The quality of work drops when there is a shortage of manpower, and if there are some favored patients in the ward as well, a significant part of the human resources are spent on them, which affects the quality of care for other patients, and they are less attended to since there are only a few of us". (P9)

Participant 6 stated: "I have ten patients as the internal ward nurse, and one of them is intubated, how am I supposed to attend to all of them? I am forced to discriminate between them and attend more to those in better conditions. I have no choice because there are only a few of us" (P6).

\subsection{Lack of access to physicians}


In this subcategory, based on their experiences, nurses cited a lack of access to physicians as one of the reasons for discrimination between patients. Since the probability of a patient's family members meeting the physician is usually very low, they try to find other ways to be more in touch with the physician. Participant 8 said:

"My brother had an accident and was hospitalized in this hospital. Because of my job and contacts, I was fully in touch with the ward and could meet my brother's doctor, and so they were more attentive and sensitive to his condition". (P8)

Also, participant 17 stated:

"The anesthesiologist came to my bedside and asked me if I knew so and so person, and I said yes. So, he told me not to worry, and everything would be done perfectly. At the time of operation, when I was highly stressed, this was very reassuring. People's presence in the operating room helped me control my stress, and their treatment was different since they knew that I was an acquaintance of this person". (P17)

\subsection{Medical centers' infrastructure}

In this subcategory, serious deficiencies, mainly physical, in the infrastructure of medical centers were identified as a facilitator of discrimination in health care. Congestion of visitors seeking outpatient clinical and paraclinical services, caused by inefficient queuing systems, unsuitable physical conditions, and similar factors, drove visitors to seek medical services through other means. Participant 17 stated:

"For example, why do they ask patients to be at the hospital at 6 o'clock? Why not ask one to come at 6.15 and so forth? When I see that my time is wasted and no one has any respect for my time, then I resort to nepotism and don't feel guilty about it' (P17).

Participant 16 stated:

"I have a fear of MRI, so I asked to be anesthetized, but the staff at the imaging department told me that there was not such an option, while there was, but they did not want to go through the trouble. Thanks to recommendations from someone I knew, my MRI was done comfortably with anesthesia. I didn't want to resort to that at first, but I was forced to, and if I had no connections, perhaps I could not do the MRI at all'. (P16)

Category four: Favoritism

This category comprises favoritism as a common and almost unavoidable issue in providing health care so that knowing someone in a medical center is one of the main reasons for choosing that center. This category mentions that finding an acquaintance in a medical center is the main concern of the patients and visitors. This category includes the following subcategories: 1) discrimination in care because 
ethnicity, 2) Favoritism as a common practice, and 3) favoritism as the ultimate solution to treatment problems.

\subsection{Discrimination in care because of ethnicity}

This subcategory mentions that medical staff regard ethnicity as a factor in providing medical care and provide better services to people of their ethnicity. Participant 13 stated:

"Where my patients come from is important to me, whether they are from the same region as me. If they are, then I feel that they have been deprived of their rights; they have spent so much money to travel from their hometown to here, and all in vain. I feel obliged to help them in any way that I can". (P13)

\subsection{Favoritism as a common practice}

This subcategory mentions favoritism by the staff, as well as by patients and visitors to health care centers, as a common and normal way of receiving medical services, so that the first thing visitors do in order to be hospitalized and receive services is to find an acquaintance, who will ultimately accelerate the provision of health services. Participant 15 stated:

"Since I am a friend of the head nurse, my work is done more rapidly, A few years ago, I had to be hospitalized in another hospital, where I knew no one, and therefore, I had to remain there for ten days. But I think if I knew someone like my friend there, things would have gone faster, and I would have been discharged earlier. Here, tests are done quickly, and the results come in, but it was not like that in the other hospital'. (P15)

\section{Participant 16 said:}

"Fortunately, I had no problems as I knew someone in the hospital who put in a word for me, and I was easily admitted, and things were done straight away. Surely it would not have been so easy otherwise. If you don't have a connection, things are delayed, or you are not hospitalized at all. It is usually like that, otherwise, I or a patient would be less attended to". (P16)

Participant 13 stated:

"There is discrimination and favoritism in admitting patients. A patient is admitted earlier, or someone rings at night to emphasize to pay more attention to a particular patient, or even comes to the hospital for the sake of that patient. But this is not done for a lot of patients. At the very most, they may ring or discharge the patient by phone. They would not visit the patient face-to-face. Another thing is ICU admission, which is highly nepotistic, and not just any patient is admitted to ICU. Some patients are admitted, and some are not". (P12)

4.3. Favoritism as the ultimate solution to treatment problems 
This subcategory points out that recipients and providers of medical services consider finding an acquaintance a strategy and a solution to their problems. The patient and medical staff both believe that having an acquaintance could help them in medical settings.

Participant 18 stated:

"As the emergency head nurse, I am frequently contacted when an intensive care bed is needed. I assess the patient and if they are likely to die, then I am not much inclined to admit them, so I tell them that there is no bed. An hour later, someone I know rings me on behalf of the patient, so I release the bed' (P18)

Also, participant 16 stated:

"Overall, I think having an acquaintance is very necessary, particularly in the matters of treatment, and with the help of a contact, things progress much better and easier, both qualitatively and quantitatively. I was given more information because I knew someone. For instance, they asked the emergency doctor to write the MRI request on insurance forms, which reduced the costs a lot compared to the noninsured service. But this is not done for all patients". (P16)

Participant 17 stated:

"I went to the clinic and I was already listed, so I was the first to be visited, which was excellent. For example, test results come in faster, or when I ring to book a time for the ultrasound, I am given a late appointment, but then I ring an acquaintance and I am the first in the queue. Ultrasound is terribly busy, but even there I am the first or second to be served. All this is because of having a friend at the hospital, otherwise, it will be exceedingly difficult". (P17)

\section{Discussion}

In this study, patients', and medical staff's experiences of discrimination in health care were explained. The results showed four main categories, including "habitual discrimination", "interpersonal relationships", "shortage of health care resources", and "favoritism".

The participants' experiences showed that discrimination is normal in medical settings so that, when visiting and receiving health care, patients had observed and experienced discriminatory behaviors on the part of health service providers. Medical staff, too, had experienced this phenomenon in providing health care to patients, as well as in the form of discriminatory behavior and provision of services of different quality to different people, as normal. Discrimination in health care in the form of the discriminatory behavior of medical staff has been identified and explained in numerous studies conducted in various countries $(13-15,34,35)$.

Regarding discrimination being normal in health care, participants had experienced different dimensions, and ignoring patient rights was one of them. In fact, patients who had not received proper medical services for any reason, and considered this experience the result of ignoring patients' primary rights, 
sought medical services through discrimination in their next visits, and their experience suggested that they would receive insufficient health services without resorting to discrimination. Johnston (2011) points out that fair access to medical services is one of the main patient rights, and patients and visitors to medical settings expect to receive these services without discriminatory behaviors (36). Accordingly, ignoring the patient's right to justice by medical staff leads to unethical and improper care, namely, discrimination in health care (37).

According to the participants' experiences, the patient, and his family members' low levels of trust in the medical staff is one of the reasons that propels patients and staff toward discrimination. In fact, this finding seems to suggest a lack of trust based on previous experiences of the visitors and the quality of medical services they received. Patients seem to distrust health care providers and their performance because of their previous experience of discrimination $(38,39)$. Another reason for the patients' lack of trust in medical personnel is the high rate of errors committed by them. In a systematic review, Assiri et al. (2018) reported errors in the administration of medications in $2 \%$ to $90 \%$ and erroneous test results in $70 \%$ of patients' (40).

According to the results of this study, interpersonal relationships of the staff was another dimension of discrimination. In medical settings, proper professional relationships are considered an effective factor in providing comprehensive and safe health care to patients (41). According to the participants' experiences, because of their friendly relationships with their colleagues, physicians and nurses provide different forms and qualities of medical services to patients associated with them. The medical staff cite colleagues' expectations, reciprocating colleagues' favors, or even the possibility of themselves or their family members getting into a similar same situation as the reasons for such discrimination. This kind of professional relationship seems to result in neglect and discriminatory and unfair behaviors in some aspects of patient care. Medical staff's lack or low levels of support for a patient who has no connections among the staff suggests unfair treatment and unethical care and a failure to abide by the principle of justice in health care (41). Patients who experience such injustice and discrimination lose their trust in the health system and medical staff.

the shortage of health care resources is another dimension of discrimination in health care, as the results of this study showed, participants stated that being faced with challenging situations at work such as a heavy workload and the shortage of medical equipment, such as vital medications, they were forced to differentiate between patients and show discriminatory behaviors in providing health care (42-44). The shortage of care resources such as workforce, equipment, medications, or physical infrastructure of medical centers has been the main concern of health organizations as a global challenge in recent decades. These shortages lead to such problems as physical and mental harm, job dissatisfaction, burnout, and more importantly, ethical challenges (45). In fact, according to their professional responsibilities, health service providers are inclined to observe ethical principles in health care, but they are faced with the question: "How?". How can they provide a high quality of care according to ethical principles when health care resources are scarce? They have no choice but to ignore some of these 
principles in providing care because in the existing situation, physical care takes priority, and the least attention is paid to ethical principles such as justice in care.

According to the results, favoritism is another dimension of discrimination in health care and a barrier to justice in providing medical services. In many countries, according to the patient rights charter, patients have the right to receive full medical services irrespective of ethnicity, culture, language, type of disease, and gender (46) while the present study participants had experienced ethnicity as one of the dimensions of discrimination in health care. Discrimination based on ethnicity and the individual's origin is one of the most common forms of discrimination in health care and has been addressed in numerous studies (4749). It seem that health service providers feel closer o people of the same ethnicity, and on the other hand, exhibit discriminatory behaviors in providing care based on differences in appearance such as skin color, language, culture, and religion, which ultimately leads to changes in the health behaviors of ethnic minorities (50).

Furthermore, the participants had experienced favoritism as a common and normal method for receiving health services of a better quality. Favoritism in medical settings has been reported as one of the main barriers to the principle of justice in ethical care (51). Favoritism is mainly enjoyed by people of a special status, such as the wealthy, those with a social or political station, and celebrities, or medical staff, such as physicians and nurses, themselves and their friends and family members. Favoritism takes the form of recommending an individual to the staff for receiving the best services in the shortest time possible (52). Since favoritism is highly prevalent in Iran, fearing a repetition of their previous experiences of receiving insufficient care, patients and visitors to medical centers attempt to find someone they know in that center, so they can receive services through favoritism (53).

According to the results, shortage of the resources must be addressed by managers because this is one of the important contexts of discrimination in healthcare. On the other hand, health system manager should develop new strategies to solving this problem. Moreover, healthcare providers as like doctors and nurses should reconsider their interpersonal relationships.

\section{Conclusion}

The results showed discrimination in health care in four dimensions of habitual discrimination, interpersonal relationships, shortage of resources, and favoritism. The participants in the study stressed that discrimination happens in health care because of various factors such as a fear of receiving insufficient care, interpersonal relationships, shortage of equipment and facilities, and patients' ethnicity. The present study can help in elucidating the concept of discrimination in health care, and accordingly, it is recommended that health system managers use these results in planning and implementing the necessary measures to control and reduce discrimination.

\section{Declarations}




\section{Ethics approval and consent to participate}

The present study was approved by the Ethics Committee of Tehran Welfare and Rehabilitation Sciences University with the code of ethics: IR.USWR.REC.1398.023. The participants studied and signed the informed consent form and were assured of the confidentiality of data and the opportunity to withdraw from the study at any time they wished.

\section{Availability of data and materials}

The datasets generated and/or analyzed during the current study are not publicly available due [REASON WHY DATA ARE NOT PUBLIC] but are available from the corresponding author on reasonable request.

\section{Competing interests}

The authors declare no conflict of interest in writing this paper.

\section{Funding}

This study had no funding source.

\section{Acknowledgments}

The present study is part of a Ph.D. thesis in nursing, approved by Tehran University of Welfare and Rehabilitation Sciences on May 29, 2019. The research team wishes to thank all participants including physicians, nurses, and nursing assistants.

\section{Author details}

1-4 Department of nursing, University of social welfare and rehabilitation sciences, Tehran, Iran.

${ }^{5}$ Department of nursing, faculty of medical sciences, University of Tarbiat Modares, Tehran, Iran.

\section{References}

1. Lemke, Viviana Guzzo. "Gender Equity in Healthcare: An Issue of Justice or Need?." Arquivos brasileiros de cardiologia vol. 113,2 299. 2 Sep. 2019, doi:10.5935/abc.20190168

2. Ghasi NC, Ogbuabor DC, Onodugo VA. Perceptions and predictors of organizational justice among healthcare professionals in academic hospitals in South-Eastern Nigeria. BMC Health Serv Res. 2020 Apr 15;20(1):301. doi: 10.1186/s12913-020-05187-5. PMID: 32293438; PMCID: PMC7158107.

3. Nguyen TT, Vable AM, Glymour MM, Nuru-Jeter A. Trends for Reported Discrimination in Health Care in a National Sample of Older Adults with Chronic Conditions. Journal of general internal medicine. 2018;33(3):291-7.

4. Whitaker KM, Everson-Rose SA, Pankow JS, Rodriguez CJ, Lewis TT, Kershaw KN, et al. Experiences of Discrimination and Incident Type 2 Diabetes Mellitus: The Multi-Ethnic Study of Atherosclerosis 
(MESA). American journal of epidemiology. 2017;186(4):445-55.

5. Abramson CM, Hashemi M, Sánchez-Jankowski M. Perceived discrimination in U.S. healthcare: Charting the effects of key social characteristics within and across racial groups. Preventive Medicine Reports. 2015;2:615-21.

6. Versey HS, Curtin N. The differential impact of discrimination on health among Black and White women. Social Science Research. 2016;57:99-115.

7. Parker LJ, Hunte H, Ohmit A. Discrimination in Health Care: Correlates of Health Care Discrimination Among Black Males. American journal of men's health. 2017;11(4):999-1007.

8. Brondolo E, Brady Ver Halen N, Pencille M, Beatty D, Contrada RJ. Coping with racism: a selective review of the literature and a theoretical and methodological critique. J Behav Med. 2009;32(1):6488.

9. Kagan SH. Ageism in Cancer Care. Seminars in Oncology Nursing. 2008;24(4):246-53.

10. Perreira KM, Telles EE. The color of health: skin color, ethnoracial classification, and discrimination in the health of Latin Americans. Soc Sci Med. 2014;116:241-50.

11. Barber C. Disability discrimination in healthcare services and employment. Nursing standard (Royal College of Nursing (Great Britain) : 1987). 2015;30(5):40-5.

12. Ginsburg OM. Breast and cervical cancer control in low and middle-income countries: Human rights meet sound health policy. Journal of Cancer Policy. 2013;1(3):e35-e41.

13. Alvarez-Galvez, Javier, and Luis Salvador-Carulla. "Perceived discrimination and self-rated health in Europe: evidence from the European Social Survey (2010).” PloS one vol. 8,9 e74252. 5 Sep. 2013, doi:10.1371/journal.pone.0074252

14. Piette JD, Bibbins-Domingo K, Schillinger D. Health care discrimination, processes of care, and diabetes patients' health status. Patient Education and Counseling. 2006;60(1):41-8.

15. van den Heuvel WJ, van Santvoort MM. Experienced discrimination amongst European old citizens. European journal of ageing. 2011;8(4):291-9.

16. Rodriguez-Alvarez E, Gonzalez-Rabago Y, Borrell LN, Lanborena N. Perceived discrimination and selfrated health in the immigrant population of the Basque Country, Spain. Gaceta sanitaria. 2017;31(5):390-5.

17. Wofford N, Defever AM, Chopik WJ. The vicarious effects of discrimination: How partner experiences of discrimination affect individual health. Social psychological and personality science. 2019;10(1):121-30.

18. Fernandez-Ballesteros R, Olmos R, Santacreu M, Bustillos A, Molina MA. The role of perceived discrimination on active aging. Archives of gerontology and geriatrics. 2017;71:14-20.

19. Whitaker KM, Everson-Rose SA, Pankow JS, Rodriguez CJ, Lewis TT, Kershaw KN, et al. Experiences of Discrimination and Incident Type 2 Diabetes Mellitus: The Multi-Ethnic Study of Atherosclerosis (MESA). Am J Epidemiol. 2017;186(4):445-55. 
20. Versey HS, Curtin N. The differential impact of discrimination on health among Black and White women. Social Science Research. 2016;57:99-115.

21. Parker LJ, Hunte H, Ohmit A. Discrimination in Health Care: Correlates of Health Care Discrimination Among Black Males. American journal of men's health. 2017;11(4):999-1007.

22. ZERO DISCRIMINATION IN HEALTH CARE SETTINGS. In: Board UPC, editor. Geneva, Switzerland2017.

23. Nivaldo Linares-Péreza OL-A. Health Equity: Conceptual Models, Essential Aspects and the Perspective of Collective Health. Social Medicine. 2008;3(3):194-206.

24. Haydt SM. Politics and Professions: Interdisciplinary Team Models and Their Implications for Health Equity in Ontario. Int J Health Serv. 2018;48(2):302-27.

25. Curtis LJ, MacMinn WJ. Health Care Utilization in Canada: Twenty-five Years of Evidence. Canadian Public Policy / Analyse de Politiques. 2008;34(1):65-87.

26. Campesino M, Saenz DS, Choi M, Krouse RS. Perceived discrimination and ethnic identity among breast cancer survivors. Oncology nursing forum. 2012;39(2):E91-100.

27. Etieyibo E, Omiegbe 0 . Religion, culture, and discrimination against persons with disabilities in Nigeria. African journal of disability. 2016;5(1):192.

28. Yasui M, Dishion TJ, Stormshak E, Ball A. Socialization of Culture and Coping with Discrimination Among American Indian Families: Examining Cultural Correlates of Youth Outcomes. Journal of the Society for Social Work and Research. 2015;6(3):317-41.

29. Martin SS, Trask J, Peterson T, Martin BC, Baldwin J, Knapp M. Influence of culture and discrimination on care-seeking behavior of elderly African Americans: a qualitative study. Social work in public health. 2010;25(3):311-26.

30. Shepherd SM, Willis-Esqueda C, Paradies Y, Sivasubramaniam D, Sherwood J, Brockie T. Racial and cultural minority experiences and perceptions of health care provision in a mid-western region. International journal for equity in health. 2018;17(1):33.

31. Hsieh H-F, Shannon S. Three Approaches to Qualitative Content Analysis. Qualitative health research. 2005;15:1277-88.

32. Graneheim UH, Lundman B. Qualitative content analysis in nursing research: concepts, procedures and measures to achieve trustworthiness. Nurse education today. 2004;24(2):105-12.

33. Misra R, Hunte H. Perceived discrimination and health outcomes among Asian Indians in the United States. BMC Health Serv Res. 2016;16(1):567.

34. Du Mont J, Forte T. Perceived discrimination and self-rated health in Canada: an exploratory study. BMC Public Health. 2016;16:742.

35. Johnstone MJ. Nursing and justice as a basic human need. Nurs Philos. 2011;12(1):34-44.

36. Lemke VG. Gender Equity in Healthcare: An Issue of Justice or Need?. Arq Bras Cardiol. 2019;113(2):299. Published 2019 Sep 2. doi:10.5935/abc.20190168. 
37. Rogers SE, Thrasher AD, Miao Y, Boscardin WJ, Smith AK. Discrimination in Healthcare Settings is Associated with Disability in Older Adults: Health and Retirement Study, 2008-2012. J Gen Intern Med. 2015;30(10):1413-20.

38. Peek ME, Wagner J, Tang H, Baker DC, Chin MH. Self-reported racial discrimination in health care and diabetes outcomes. Med Care. 2011;49(7):618-25.

39. Assiri GA, Shebl NA, Mahmoud MA, et al. What is the epidemiology of medication errors, error-related adverse events and risk factors for errors in adults managed in community care contexts? A systematic review of the international literature [published correction appears in BMJ Open. 2019 May 27;9(5):e019101corr1]. BMJ Open. 2018;8(5):e019101. Published 2018 May 5. doi:10.1136/bmjopen-2017-019101

40. Atinga R, Bawole JN, Nang-Beifubah A. 'Some patients are more equal than others': Patient-centered care differential in two-tier inpatient ward hospitals in Ghana. Patient Educ Couns. 2016;99(3):370-7.

41. Ludwick R, Silva MC. Errors, the nursing shortage and ethics: survey results. Online journal of issues in nursing. 2003;8(3):9.

42. Erlen JA. The nursing shortage, patient care, and ethics. Orthopedic nursing. 2001;20(6):61-5.

43. Erlen JA. Wanted-nurses. Ethical issues and the nursing shortage. Orthopedic nursing. 2004;23(4):289-92.

44. Scott PA, Harvey C, Felzmann H, et al. Resource allocation and rationing in nursing care: A discussion paper. Nurs Ethics. 2019;26(5):1528-1539. doi:10.1177/0969733018759831.

45. VanderPlaat $M$, Teles N. Mainstreaming social justice: human rights and public health. Can J Public Health. 2005;96(1):34-36. doi:10.1007/BF03404011.

46. Sabbah W, Gireesh A, Chari M, Delgado-Angulo EK, Bernabe E. Racial Discrimination and Uptake of Dental Services among American Adults. Int J Environ Res Public Health. 2019;16(9).

47. Macintosh T, Desai MM, Lewis TT, Jones BA, Nunez-Smith M. Socially-assigned race, healthcare discrimination and preventive healthcare services. PLoS One. 2013;8(5):e64522.

48. Fazeli Dehkordy S, Hall KS, Dalton VK, Carlos RC. The Link Between Everyday Discrimination, Healthcare Utilization, and Health Status Among a National Sample of Women. J Womens Health (Larchmt). 2016;25(10):1044-51.

49. Moscoso-Porras MG, Alvarado GF. Association between perceived discrimination and healthcareseeking behavior in people with a disability. Disabil Health J. 2018;11(1):93-8.

50. Rooddehghan Z, Nikbakht Nasrabadi AL, Parsa Yekta Z. Components of equity-oriented health care system: perspective of Iranian nurses. Glob J Health Sci. 2014;7(2):94-100.

51. Georges EM, Anzia J, Dinwiddie SH. General effect of VIP patients on delivery of care. Psychiatry Ann. 2012;42(1):15-9.

52. Rooddehghan Z, Nasrabadi A, Parsa Yekta Z, Salehi M. Patient Favoritism as a Barrier to Justice in Health Care: A Qualitative Study. Health Spiritual Med Ethics. 2019;6(4):29-35. 